\title{
Choosing Open Source ERP Systems: What Reasons Are There For Doing So?
}

\author{
Björn Johansson and Frantisek Sudzina \\ Copenhagen Business School, Center for Applied ICT, Frederiksberg, Denmark \\ $\{$ bj.caict, fs.caict $\}$ acbs.dk
}

\begin{abstract}
Enterprise resource planning (ERP) systems attract a high attention and open source software does it as well. The question is then if, and if so, when do open source ERP systems take off. The paper describes the status of open source ERP systems. Based on literature review of ERP system selection criteria based on Web of Science articles, it discusses reported reasons for choosing open source or proprietary ERP systems. Last but not least, the article presents some conclusions that could act as input for future research. The paper aims at building up a foundation for the basic question: What are the reasons for an organization to adopt open source ERP systems.
\end{abstract}

\section{Introduction}

In the last decade, an explosive interest have been shown in enterprise resource planning (ERP) systems as well as in free and open source software (FOSS) systems. In this paper, we aim at presenting the status of the combination of these two areas, namely open source ERP systems. This is interesting at least for two reasons. Firstly, the development model of open source has changed during the latest years and the question is how the "new" development model for open source influences future development of ERP systems. Secondly, software vendors of proprietary ERP systems face some challenges, which they need to take care of, if they should be able to stay in the business also in the future. The basic question discussed in the paper is: What reasons are there for adopting open source ERP systems?

The rest of the paper is organized in the following way: section 2 introduces the subject by giving definitions of ERP and section 3 of the open source development. Section 4 then discusses open source ERP systems and describes the status of open source ERP systems. Section 5 includes results from a literature review on ERP system selection criteria and discusses how open source and proprietary ERP systems fulfill them. The final section of the paper offers few suggestions for future research related to adoption of open source ERP systems.

\section{Enterprise Resource Planning Systems}

ERP systems have received a lot of attention in the last years and there are many ERP system research instances and quite a lot of reviews, e.g. Shehab, Sharp, Supramaniam, 
and Spedding [1], Esteves and Pastor [2] and Botta-Genoulaz, Millet and Grabot [3]. ERP systems emerged in the 1950s and 1960s when computers were introduced in organizations [4]. This software is often defined as standardised packaged software designed with the aim of integrating the entire value chain in an organization $[5,6]$. Wier et al. [7] argue that ERP systems aim to integrate business processes and ICT into a synchronized suite of procedures, applications and metrics which goes over firms' boundaries. Kumar et al. [8] say ERP systems originated in the manufacturing industry, where the first generation of ERP systems was introduced. According to Kumar and van Hillegersberg, development of the first generation ERP systems was an inside-out process, going from standard inventory control (IC) packages, to material requirements planning (MRP), material resources planning (MRP II) and then further on expanding it to a software package that aims to support the entire organization (second generation ERP systems). This evolved software package is then described as the next generation ERP system labeled as ERP II system which, according to Møller [4], could be described as the next generation enterprise systems (ES). This development has increased the complexity both when it comes to usage as well as development of ERP systems. The complexity comes from the fact that ERP systems are systems that are supposed to integrate the organization, both inter-organizational as well as intra-organizational, and its business process in a one suite package [9]. It can be stated that ERP systems as well as the way how organizations use ERP systems have changed a lot. However, these changes influenced also the way how ERP systems are developed and sold. It can be suggested that the ERP system market is a market that changes a lot all the time. This impacts what stakeholders there are in an ERP system value-chain $[10,11]$ but also how these different stakeholders receive competitive advantage from ERP systems. It can be clearly argued that an organization does not receive competitive advantage by just implementing an ERP system any longer [12, 13], and one reason for that could be that ERP systems focus on best practices. The question could then be if an organization adopts open source ERP systems since decision-makers in the organization see open source ERP systems as the way of having a system that makes them different from competitors.

It may be suggested that ERP systems are complex business applications and the complexity has increased when the software has matured. It may be also suggested that the complexity to a high extent influences development, since the software aims at supporting the entire organization's business processes. This makes that ERP systems need to have a high level of functionality adopted which are supposed to support internal processes as well as external processes.

When reviewing existing literature on ERP systems such as for instance Shehab et al., [1], Esteves and Pastor [2] and Botta-Genoulaz et al., [3] it is found that a major part of the research is on implementation of ERP systems. It also shows that the main problem presented is the misfit between ERP system functionality and business requirements. Soh, Kien and Tay-Yap [14] describe this as a common problem when adopting software package. The problem of "misfit" means that there is a gap between functionality offered by the package and functionality required from the adopting organization. It could be asked whether new delivery models for ERP systems and ERP system related services such as application service provision (ASP) or software as a service (SaaS) solve this problem. Another delivery model worth mentioning is a combination of delivery model and development model, is the open 
source phenomenon. The next section will describe open source as a phenomenon and the reason for doing so is to build up the base for later discussion of the question: What reasons are there for adopting open source ERP systems?

\section{Open Source Software}

The origin of open source software can, according to Hars and Qu [15], be traced back to the 1950s and 1960s. They describe it as that when software was sold, macros and utilities were freely exchanged in user forums. However, the real take-off of open source software was probably when Richard Stallman founded the Free Software Foundation (FSF) that provided the conceptual foundation for open source software. Bruce, Robson and Spaven [16] suggest that open source is mature and industrystrength in many areas. The areas, which they give as examples, are operating systems, application servers and security tools. When it comes to applications, they state open source is not a mature area. However, they suggest that some exceptions from this are business applications such as customer relationship management (CRM), ERP, content management, and business intelligence. Bruce et al., [16] describe this as the third wave of open source adoption. The first wave being the adoption of open source as operating systems, the second wave then adoption of open source as infrastructure systems (middleware, browsers, databases).

Riehle [17] states that there are two different types of open source software, community open source and commercial open source. Riehle describes these two types in the following way: Community open source is software developed by a community while commercial open source is software that a for-profit entity owns and develops. These types differ in who decides on the future direction of the software. In the community case, individual developers, often in the form of a broad community of volunteers, decides on which contributions that should be accepted in the source code base. The "community" also decides on where the software is heading. In the commercial case a company decides on what should be accepted into the software code base. In this case the company also maintains the copyright and decides what to implement next. This means that in the commercial open source there are market-entry barriers. In the community open source situation no market-entry barriers exist, and therefore can, given the right license, anyone set up a company and start selling software according to Riehle [17]. What he states is that if someone starts a company delivering open source software they will not sell the software as such, instead will they sell its provision, maintenance, and support.

Riehle [17] describes costs as one reason why organizations adopt open source. However, he states that the open source cost perspective is mainly a reason for solution providers. The reason for this is that the customer pays for the software he or she uses from a market perspective. This means that customers pay the fee that the market demands. If then the solution provider can produce the software solution cheaper by using open source, they can increase their profit or increase the cost for delivered services to each costumer. According to Riehle [17] the result of this is that solution providers gain the most from open source software because they increase profits through direct cost savings and the ability to reach more customers through improved pricing flexibility. Economides and Katsamakas [18] stipulate that open source, despite the fact that it can be used for free, has costs related to the usage. 
Costs related are costs of learning, costs for installing, and costs for maintaining. But there can also be higher support costs than for proprietary software.

According to Câmara and Fonseca [19], open source software can be beneficial for developing countries in two ways, namely as a means of reducing licensing costs, and promoting indigenous technological development by having source code of these products. A document on intellectual property rights and international development commissioned by the government of the United Kingdom underpins that "developing countries and their donor partners should review policies for procurement of computer software, to ensure that options for using low-cost and/or open source software products are properly considered and their costs and benefits carefully evaluated" [20]. Other reasons for the adoption of open source software in developing countries include avoiding being hostage to proprietary software [21], advancing knowledge more quickly [22], and helping to set up an information economy [23]. All these reasons apply also for open source ERP systems.

Hars and Qu [15] discuss motivations for why individuals participate in open source projects. They state that individuals' motivations can be categorized into two broad categories: internal factors and external rewards. These two categories are said to be a result of three factors, namely: social motivations, collective motivations, and reward motivations. Proponents of open source emphasize that open source programmers are not motivated by monetary incentives. Instead they are said to be motivated by their personal hobbies and preferences or by the rewarding sense that they increase the welfare of others [15]. Regarding information support, according to the research of Lakhani and von Hippel [24], people respond to questions because they expect reciprocity, they "help the cause" (i.e. like the idea of open source software), they expect to gain reputation or enhance their career prospects, they consider answering questions to be intrinsically rewarding, and for some, it is part of their job (in case they work in a company, which sells a commercionalized version of the software along with documentation and support).

Although it may seem that there many benefits stemming from usage of open source software, there are not too many companies who adopt it. Goode [25] conducted research on a sample of 500 Australia's top companies in order to figure out why their managers rejected open source software. According to his findings, the main reasons is that managers perceive no relevance in its offerings, are concerned about unreliable or transient support sources, lack available resources, or perceive no requirement for open source technology in their businesses. The smallest groups noted that they did not have time to implement it; they were already using commercial closed source software. This suggests that at least some respondents see the adoption of and migration towards open source software as a significant undertaking, with a long and steep learning curve.

Last but not least, there is a question of measurement of an open source software package "market" share. When software has no price, no purchase contracts and no buyers and sellers, it may be difficult to estimate its impact. Thain, Tannenbaum and Livny [26] addressed this problem and came up with three advices: plan for measurement far in advance, use multiple techniques to collect data, and give the users stake in the measurement. These advices are meant mainly for project teams developing open source software and cannot be easily utilized by researchers. Another approach to estimation of the number of open source ERP systems is used in the next chapter. 


\section{The Status of Open Source ERP Systems}

There is no doubt that there is a great interest in open source. However, the question remains if this could be said also about open source ERP systems. In order to get some kind of answer to this question, we made an investigation of the distribution channel SourceForge. SourceForge is as said above a distribution channel of open source projects and on the website it states the following "SourceForge.net is the world's largest Open Source software development web site. SourceForge.net provides free hosting to Open Source software development projects with a centralized resource for managing projects, issues, communications, and code". (www.SourceForge.net). In order to get a grasp of the status over open source ERP systems, a search was made in November 2007 and the same search was then made in November 2008. The search showed that there were 356 open source ERP system projects registered on 27 November 2007. On 13 November 2008, there were 447 open source projects registered. This means that in a year, there had been an increase of 91 new open source ERP system projects. An interesting finding is that new projects are to a high extent connected to existing projects, what means that they have a focus on developing ERP systems for specific industries and so on. Another way of showing the interest in open source ERP systems is to look into downloads of the software as such. However, it is important to remember that downloads do not say anything about actual adoption and usage as such. But, it can be assumed that if the downloads increase the adoption rate probably also increases. To have some idea about this, we looked into downloads of six different open source ERP systems. These open source ERP systems were chosen from a recommendation made by a consultant working in the open source ERP system sector. In Table 1, we show the statistics about downloads from these six open source ERP system projects.

Table 1. Download of selected open source ERP systems

\begin{tabular}{|l|r|r|r|c|}
\hline $\begin{array}{l}\text { Downloads/Open } \\
\text { source ERP system }\end{array}$ & $\begin{array}{r}27 \text { November } \\
2007\end{array}$ & $\begin{array}{r}\text { 13 November } \\
2008\end{array}$ & $\begin{array}{r}\text { Downloads during } \\
\text { almost a year }\end{array}$ & $\begin{array}{c}\text { Start of the } \\
\text { project }\end{array}$ \\
\hline Compiere & 1296098 & 1431226 & 135128 & $2001-06-08$ \\
\hline OpenBravo & 401262 & 828465 & 427203 & $2006-03-09$ \\
\hline Opentaps & 311964 & 406848 & 94884 & $2005-08-10$ \\
\hline Facturalux & 235897 & 251306 & 15409 & $2001-03-16$ \\
\hline WebERP & 149010 & 208121 & 59111 & $2003-01-07$ \\
\hline TinyERP & 21116 & 50249 & 29113 & $2005-03-25$ \\
\hline
\end{tabular}

Table 1 implies that open source ERP systems have existed for several years. It also shows that the interest seems to have increased, since there have been an intensive amount of downloads lately. As mentioned earlier, downloading an ERP does not equal to ERP system adoption.

An interesting question arises from the note - what are the reasons for adoption of open source ERP systems. To get a grasp over this it could be interesting to go through commonly stated ERP system selection criteria and compare proprietary and open source ERP systems. 


\section{Selection of ERP Systems}

This section provides results from a literature review of ERP system selection criteria based on articles published in journals covered by Web of Science. It also discusses these criteria with respect to open source and proprietary ERP systems.

In order to identify important criteria for ERP system selection process, we conducted literature review of articles fulfilling the query:

Topic $=($ "enterprise resource planning") AND Topic $=($ select* OR choos* OR chose* $)$

The string "enterprise resource planning" (not "enterprise resource planning system") has been chosen because articles often provide the acronym in brackets right after "enterprise resource planning", so an alternative string would exclude articles with the acronym or we would need to expand the part of the query searching for ERP system articles. The acronym was not used because all the articles with a substring of "erp" (i.e. almost all articles) would be selected. The second part of the query tries to account for the selection process. The Web of Science database has been used because it contains a reasonable number of high quality articles.

Table 2. ERP system selection criteria

\begin{tabular}{|c|c|c|}
\hline Criterion & No. & Articles \\
\hline Ease/speed of implementation & 12 & {$[27][28][29][30][31][32][33][34][35][36][37][38]$} \\
\hline Price & 11 & [39] [27] [28] [29] [30] [40] [31] [33] [34] [37] [38] \\
\hline Vendor support & 10 & [39] [28] [41] [42] [40] [31] [32] [33] [34] [37] \\
\hline Reliability & 9 & [39] [27] [29] [41] [42] [33] [35] [36] [38] \\
\hline Ease of use & 9 & [39] [27] [29] [32] [33] [34] [43] [35] [36] \\
\hline Customization/parameterization & 8 & [44] [27] [29] [41] [42] [32] [34] [36] \\
\hline Integration & 8 & {$[27][28][41][42][32][45][43][37]$} \\
\hline Organizational fit & 7 & [46] [41] [42] [30] [47] [31] [38] \\
\hline Functionality & 7 & [39] [29] [41] [42] [33] [45] [38] \\
\hline Vendor reputation & 7 & [29] [41] [42] [30] [32] [33] [38] \\
\hline Flexibility & 6 & [39] [31] [33] [35] [36] [38] \\
\hline Training & 6 & {$[28][32][34][35][36][37]$} \\
\hline Information needs & 5 & {$[44][27][47][45][43]$} \\
\hline Latest technologies & 4 & [39] [41] [42] [40] \\
\hline Scalability & 4 & {$[28][48][32][37]$} \\
\hline Upgrades & 3 & [41] [42] [40] \\
\hline Modularity & 3 & [27] [41] [42] \\
\hline
\end{tabular}

As of 15 November 2008, there were 58 journal articles fulfilling the query. Out of these 58 articles, 22 contained lists of criteria. In most cases, these were ERP selection criteria. In a few case, these were rather satisfaction criteria with the already implemented ERP system. But since the same criteria could have been used also prior to the implementation, we included them in our sample. Since enumeration of 
individual lists would take a lot of space, Table 2 provides a summary of the criteria. Similar concepts are grouped together, since there were a number of criteria, which were mentioned only in a few articles, only criteria with at least three occurrences are presented.

These criteria will be discussed in the following subsections with respect to open source and proprietary ERP systems.

\subsection{Criterion 1 Ease/Speed of Implementation}

There exist a sentiment that implementation takes too long [49]. It is hard to state whether proprietary or open source ERP systems are faster and easier to implement. On one hand, open source solutions are, in general, believed to be less user-friendly. On the other hand, ERP vendors (or their partners) implement proprietary ERPs, so there is no clear need for them to make ERP systems easy to install. However, it can be stated that if the ERP system is easier to implement then it would be possible for the ERP vendor to sell more licenses, since it can be assumed that there is a lack of implementing consultants.

Moreover, ease and speed of implementation does not depend only on the graphical user interface and number of settings one needs to select from but mainly on the amount of required customizations. Further development does not depend only a programmer's speed of writing code but also on requirements collection, their analysis and correct understanding.

\subsection{Criterion 2 Price}

Unless the company has the capabilities to implement an open source ERP system and program all the necessary customizations, open source ERP is not really for free. Consultants for open source ERP systems may charge significantly more than e.g. consultants for MS ERP systems [50], since there are rather only a few of them.

On the other hand, an open source ERP system can be a perfect solution for a starting company, which has no established business processes - the company can adapt to the system, i.e. it does not require customization, so consultants need to be hired only to install the system. Another advantage is that an open source ERP system can be adjusted directly to the intended business processes in case at least one of the employees has a good computer science background.

\subsection{Criterion 3 Vendor Support}

Though this criterion seems to be more important for proprietary ERP systems, since it is customers of proprietary ERP systems, who are locked in with the vendors but on the other hand, they have security that the support exists. In the open source world, this criterion can be interpreted as having a large enough community, which could support the organization implementing a particular open source ERP system.

\subsection{Criterion 4 Reliability}

Vendors providing proprietary ERP systems try to achieve as high reliability as possible but community using an open source ERP system might be able to find errors 
faster, since it is larger in numbers and each of them tries to make sense of code. While in proprietary ERP system vendor organization, it is always the same people looking into the code, so it is much harder for them to spot a mistake, especially in the code, which was written by themselves.

\subsection{Criterion 5 Ease of Use}

It is unclear whether proprietary or open source ERP systems are easier to use. On one hand, ERP system vendors try to achieve competitive advantage providing ERP systems that are easier to use. On the other hand, open source solutions are, in general, believed to be less user-friendly $[51,52]$. But the community of users (with programming skills) is likely to improve the system to the level that is more-or-less acceptable for most of the users.

\subsection{Criterion 6 Customization/Parametrization}

Proprietary ERP systems are often programmed in vendor-specific languages. Companies can be sure that vendors (or their partners) will customize and set up their ERP systems. But it also means that they are locked to the vendor (or its partners). Since open source ERP systems are programmed in widely known programming languages, there is a greater pool of potential programmers, who can do it. Openness of code is not a domain of OSS ERPs anymore. E.g. MS Dynamics AX allows users to change a significant percentage of the code.

\subsection{Criterion 7 Integration}

Customers are often searching for means of integration of their systems/data. Many proprietary ERP systems inherently allow for usage of data warehouses. It is possible that there fewer proprietary than open source ERP systems, which allow for communication to other systems through API. On the other hand, this communication can be solved even by less standard means (through customization).

\subsection{Criterion 8 Organizational Fit}

Existing ERP systems try to focus on business processes, however it can be suggested that they do not explicitly describe the business processes that are supported. Besides that, ERP systems are not easily adjustable to changes in business processes. Unfortunately, it seems that this is a problem of both open source and proprietary ERP systems.

\subsection{Criterion 9 Functionality}

When it comes to functionalities offered by ERP systems, proprietary ERP systems may offer more of them (because of the longer time the vendor has been in this business) but open source ERP systems, since they offer a smaller total number of them, may be easier to master than proprietary ERP systems. 


\subsection{Criterion 10 Vendor Reputation}

This criterion is obviously not relevant for open source ERP systems, since one can investigate the software without any prior commitment unlike the case of proprietary ERP systems. Vendor reputation can be understood as an approximation for ERP system quality if the case is that potential users cannot examine the software in detail before purchase.

\subsection{Criterion 11 Flexibility}

Flexibility is required because of rapidly changing environment, which is likely to lead to new business models, which need to be supported without disturbing the endusers and on-going business. This requires an ERP system to have a robust architecture, which would allow for these requirements. Many existing proprietary ERP systems arose from MRP systems through small iterations. So systems, which were created more recently and do not carry this burden, are more likely to be more flexible, which could be the case with open source ERP systems.

\subsection{Criterion 12 Training}

First, it can be said that the amount of training required depends on the ERP systems how self-explanatory it is and how many functions it offers. Secondly, users of proprietary ERP systems are more-or-less dependent on the vendor or partners related to the specific ERP system. On the other hand, users of open source ERP systems may have a hard time to find a consultancy company offering training for a particular system.

\subsection{Criterion 13 Information Needs}

Organizations expect to get better information due to the usage of ERP systems. Probably all ERP systems improve quality of information. But what organizations really want is a better access to data. In other words, it is mainly reporting capabilities they are interested in. Companies often require reports, which were not anticipated when creating the ERP system. In this case open source ERP systems may prove better, since it is easier to customize them. It is also easier to customize an open source ERP system to include additional columns in the underlying database, however, it demands that the end-user have enough knowledge to do that.

\subsection{Criterion 14 Latest Technologies}

There is no reason why proprietary ERP systems should be better in using latest technology but it is mostly vendors of proprietary ERP systems, who claim that their competitive advance (over other (regardless whether open source or proprietary) ERP systems) is usage of latest technology. Proprietary vendors may promote them more but similar solutions may exist in the open source world. 


\subsection{Criterion 15 Scalability}

Scalability is especially important for companies, which plan for a longer time period and also plan for substantial growth. Unfortunately, there are many both open source and proprietary systems, are optimized (or not optimized at all and therefore suitable) only for certain size of organizations (especially small and medium enterprises). Even such well-known vendor as SAP was not able to make its ERP system to fit all and instead of downsizing of SAP ERP (i.e. R/3), it purchased another ERP system, which are sold to smaller customers as SAP Business One.

\subsection{Criterion 16 Upgrades}

Upgrades for open source ERP systems are for free, while customers of proprietary ERPs have to purchase upgrades or pay an annual fee, which allows them to get upgrades for free. But it is also true that there is a relation between customization and the costs for cost for upgrade of ERP systems that are highly customized. Proprietary vendors are more likely to look deeper into customizations, which might be affected by the upgrade. In the worst case, the upgrade may require reprogramming of the entire previous customization.

Regarding support, it is assumed that users of OSS ERPs always install the newest upgrade and only the latest version is supported. Vendors of proprietary ERPs always provide support of several (in some cases, for all) versions of their ERP. Upgrades for OSS ERPs appear at time a bug is found or somebody takes effort to program something better or new. Vendors of proprietary ERPs try to minimize the number of upgrades, since supporting too many versions is costly.

\subsection{Criterion 17 Modularity}

When it comes to modularity, there exist extreme examples (monolithic and modular) both in open source and proprietary ERP systems. A suitable architecture may allow programming a completely new module for both open source and proprietary ERP systems. Regarding actual availability of modules, there are probably most modules available for SAP ERP.

\section{Concluding Remarks and Future Research}

Open source ERPs seem to be of an increasing interest at the moment. It could be asked if this interest is a result of dissatisfaction with proprietary ERPs or if it is a result of maturity in the open source phenomenon. When looking at selection criteria, we cannot conclude whether open source or proprietary solutions would be more suitable for majority of organizations.

In the more and more and global environment that ERPs operate, it could also be of interest to investigate whether there are any differences in open source ERP systems adoption in developed and under developed/developing countries. One statement, according to IEMC [53], when it comes to proprietary ERP systems is that most of the ERP software is developed in technically advanced countries, standards are often too high for under developed or developing countries. In an effort to bring the global 
organization to a common platform, different countries would need different levels of upgrades, and maybe the open source ERP system option could deliver that.

However, returning back to the question: What reasons are there for adopting open source ERP systems, and the presentation of ERP system selection criteria in Table 2, it can be said that among the four most reported criteria the most obvious difference between open source ERP and proprietary ERP is the price, and that comes on second place. On the first place, in the form of most reported selection criteria, comes ease/speed of implementation, and it can be suggested that also implementation differs a lot between the two options, since, at least according to the proponents' of open source, is open source ERP implementation just "to download". Vendor support and reliability is then on place three and four, it can definitely say that these two criteria are related to each other and it can also be said that when comparing the two options, open source ERP and proprietary ERP, it can be concluded that the proprietary ERP seems to be better. It would, definitely, be interesting to do more research about these statements, especially since the reported selection criteria, in Table 2, to a high extent are not retrieved from empirical studies.

\section{References}

1. Shehab, E.M., Sharp, M.W., Supramaniam, L., Spedding, T.A.: Enterprise resource planning: An integrative review. Bus. Process Manag. J. 10, 359-386 (2004)

2. Esteves, J., Pastor, J.: Enterprise Resource Planning Systems Research: An Annotated Bibliography. Communications of AIS 7, 1-51 (2001)

3. Botta-Genoulaz, V., Millet, P.A., Grabot, B.: A survey on the recent research literature on ERP systems. Computers in Industry 56, 510-522 (2005)

4. Møller, C.: ERP II: a conceptual framework for next-generation enterprise systems? J. of Enterp. Inf. Manag. 18, 483-497 (2005)

5. Lengnick-Hall, C.A., Lengnick-Hall, M.L., Abdinnour-Helm, S.: The role of social and intellectual capital in achieving competitive advantage through enterprise resource planning (ERP) systems. J. of Engineering and Technology Manag. 21, 307-330 (2004)

6. Rolland, C., Prakash, N.: Bridging the Gap Between Organisational Needs and ERP Functionality. Requirements Engineering 5, 180-193 (2000)

7. Wier, B., Hunton, J., HassabElnaby, H.R.: Enterprise resource planning systems and nonfinancial performance incentives: The joint impact on corporate performance. International J. of Account. Inf. Systems 8, 165-190 (2007)

8. Kumar, K., Van Hillegersberg, J.: ERP experiences and evolution. Communications of the ACM 43, 22-26 (2000)

9. Koch, C.: ERP-systemer: erfaringer, ressourcer, forandringer. Ingeniøren-bøger København, $224(2001)$

10. Ifinedo, P., Nahar, N.: ERP systems success: an empirical analysis of how two organizational stakeholder groups prioritize and evaluate relevant measures. Enterp. Inf. Systems 1, 25-48 (2007)

11. Somers, T.M., Nelson, K.G.: A taxonomy of players and activities across the ERP project life cycle. Inf. \& Manag. 41, 257-278 (2004)

12. Karimi, J., Somers, T.M., Bhattacherjee, A.: The Impact of ERP Implementation on Business Process Outcomes: A Factor-Based Study. J. of Manag. Inf. Systems 24, 101134 (2007) 
13. Kocakulah, M.C., Embry, J.S., Albin, M.: Enterprise Resource Planning (ERP): managing the paradigm shift for success. International J. of Inf. and Operations Manag. Education 1, 125-139 (2006)

14. Soh, C., Kien, S.S., Tay-Yap, J.: Cultural fits and misfits: Is ERP a universal solution? Communications of the ACM 43, 47-51 (2000)

15. Hars, A., Qu, S.: Working for Free? Motivations for Participating in Open-Source Projects. International J. of Electronic Commerce 6, 25 (2002)

16. Bruce, G., Robson, P., Spaven, R.: OSS opportunities in open source software - CRM and OSS standards. BT Technology J. 24, 127-140 (2006)

17. Riehle, D.: The Economic Motivation of Open Source: Stakeholders Perspectives. Computer 40, 25-32 (2007)

18. Economides, N., Katsamakas, E.: Two-Sided Competition of Proprietary vs. Open Source Technology Platforms and the Implications for the Software Industry. Manag. Science 52, 1057-1071 (2006)

19. Câmara, G., Fonseca, F.: Information policies and open source software in developing countries. J. of the American Society for Inf. Science and Technology 58, 121 (2007)

20. Barton, J., Alexander, D., Correa, C., Mashelkar, R., Samuels, G., Thomas, S.: Integrating intellectual property rights and development policy. UK Department for International Development, Commission on Intellectual Property Rights, London (2002)

21. United Nations, Road maps towards an information society in Latin America and the Caribbean. (No. LC/G.2195/Rev.1-P) United Nations Economic Commission for Latin America and the Caribbean, Santiago, Chile (2004)

22. United Nations, E-commerce and development report. (No. UNCTAD/SIDTE/CB/2003/1) United Nations, New York/Geneva (2003)

23. Weerawarana, S., Weeratunga, J.: Open source in developing countries (No. SIDA3460en) Sida Department for Infrastructure and Economic Cooperation, Stockholm (2004)

24. Lakhani, K.R., von Hippel, E.: How open source software works: "free" user-to-user assistance. Research Policy 32, 923-943 (2003)

25. Goode, S.: Something for nothing: management rejection of open source software in Australia's top firms. Inf. \& Manag. 42, 669-681 (2005)

26. Thain, D., Tannenbaum, T., Livny, M.: How to measure a large open-source distributed system. Concurrency and Computation: Practice and Experience 18, 1989-2019 (2006)

27. Bueno, S., Salmeron, J.L.: Fuzzy modeling Enterprise Resource Planning tool selection. Computer Standards \& Interfaces 30, 137-147 (2008)

28. Fisher, D.M., Fisher, S.A., Kiang, M.Y., Chi, R.T.: Evaluating mid-level ERP software. J. of Computer Inf. Systems 45, 38-46 (2004)

29. Keil, M., Tiwana, A.: Relative importance of evaluation criteria for enterprise systems: a conjoint study. Inf. Systems J. 16, 237-262 (2006)

30. Lall, V., Teyarachakul, S.: Enterprise Resource Planning (ERP) System selection: A Data Envelopment Anaysis (DEA) approach. J. of Computer Inf. Systems 47, 123-127 (2006)

31. Umble, E.J., Haft, R.R., Umble, M.M.: Enterprise resource planning: Implementation procedures and critical success factors. European J. of Operational Research 146, 241-257 (2003)

32. Verville, J., Halingten, A.: A six-stage model of the buying process for ERP software. Industrial Marketing Manag. 32, 585-594 (2003)

33. Wei, C.C., Chien, C.F., Wang, M.J.J.: An AHP-based approach to ERP system selection. International J. of Production Economics 96, 47-62 (2005)

34. Yang, J.B., Wu, C.T., Tsai, C.H.: Selection of an ERP system for a construction firm in Taiwan: A case study. Automation in Construction 16, 787-796 (2007) 
35. Wu, J.H., Wang, Y.M.: Measuring ERP success: the ultimate users' view. International J. of Operations \& Production Manag. 26, 882-903 (2006)

36. Wu, J.H., Wang, Y.M.: Measuring ERP success: The key-users' viewpoint of the ERP to produce a viable IS in the organization. Computers in Hum. Behavior 23, 1582-1596 (2007)

37. Ahn, B.S., Choi, S.H.: ERP system selection using a simulation-based AHP approach: a case of Korean homeshopping company. J. of the Operational Research Society 59, 322 $330(2008)$

38. Malie, M., Duffy, N., van Rensburg, A.C.J.: Enterprise resource planning solution selection criteria in medium-sized South African companies. S. Afr. J. of Industrial Engineering 19, 17-30 (2008)

39. Ayağ, Z., Özdemir, R.G.: An intelligent approach to ERP software selection through fuzzy ANP. International J. of Production Research 45, 2169-2194 (2007)

40. Rao, S.S.: Enterprise resource planning: business needs and technologies. Industrial Manag. \& Data Systems 100, 81-88 (2000)

41. Kumar, V., Maheshwari, B., Kumar, U.: Enterprise resource planning systems adoption process: a survey of Canadian organizations. International J. of Production Research 40, 509-523 (2002)

42. Kumar, V., Maheshwari, B., Kumar, U.: An investigation of critical management issues in ERP implementation: emperical evidence from Canadian organizations. Technovation 23, 793-807 (2003)

43. Spathis, C., Constantinides, S.: The usefulness of ERP systems for effective management. Industrial Manag. \& Data Systems 103, 677-685 (2003)

44. Berchet, C., Habchi, G.: The implementation and deployment of an ERP system: An industrial case study. Computers in Industry 56, 588-605 (2005)

45. Oliver, D., Whymark, G., Romm, C.: Researching ERP adoption: an internet-based grounded theory approach. Online Inf. Review 29, 585-603 (2005)

46. Bernroider, E.W.N., Stix, V.: Profile distance method- a multi-attribute decision making approach for information system investments. Decision Support Systems 42, 988-998 (2006)

47. Nah, F.F.H., Delgado, S.: Critical success factors for enterprise resource planning implementation and upgrade. J. of Computer Inf. Systems 46, 99-113 (2006)

48. Han, S.W.: ERP - Enterprise resource planning: A cost-based business case and impleentation assessment. Hum Factors and Ergonomics in Manufacturing 14, 239-256 (2004)

49. Basoglu, N., Daim, T., Kerimoglu, O.: Organizational adoption of enterprise resource planning systems: A conceptual framework. J. of High Technology Manag. Research 18, 73-97 (2007)

50. Danielsson, L.: Öppen källkod dubblar lönen (2007), http: / /www.idg.se/2.1085/1.135393 (accessed December 10, 2007)

51. Levesque, M.: Fundamental issues with open source software development. First Monday 9 (2004)

52. Geldenhuys, W.J., Gaasch, K.E., Watson, M., Allen, D.D., Van der Schyf, C.J.: Optimizing the use of open-source software applications in drug discovery. Drug Discovery Today 11, 127-132 (2006)

53. Ghosh, S.: Challenges on a global implementation of ERP software. In: Engineering Manag. Conference, IEMC, pp. 101-106 (2002) 